Article

\title{
Effect of Salinity on the Gut Microbiome of Pike Fry (Esox lucius)
}

\author{
Tomasz Dulski ${ }^{1, *} \mathbb{0}$, Roman Kujawa ${ }^{2}$, Martyna Godzieba ${ }^{1}$ and Slawomir Ciesielski ${ }^{1}$ \\ 1 Department of Environmental Biotechnology, University of Warmia and Mazury in Olsztyn, 10-709 Olsztyn, \\ Poland; martyna.godzieba@gmail.com (M.G.); slavcm@uwm.edu.pl (S.C.) \\ 2 Department of Ichthyology and Aquaculture, University of Warmia and Mazury in Olsztyn, 10-719 Olsztyn, \\ Poland; reofish@uwm.edu.pl \\ * Correspondence: tomasz.dulski@uwm.edu.pl; Tel.: +48-89-523-41-64
}

Received: 15 February 2020; Accepted: 1 April 2020; Published: 5 April 2020

check for updates

\begin{abstract}
The increasing popularity of pike in angling and fish farming has created a need to increase pike production. However, intensive pike farming is subject to limitations due to diseases and pathogens. Sodium chloride $(\mathrm{NaCl})$ could be a good alternative to chemotherapeutics, especially for protecting the fish against pathogens and parasites at early life stages. However, the impact of high salinity on the symbiotic bacteria inhabiting freshwater fish is still unclear. Therefore, our objective was to analyze the gut microbiome to find possible changes caused by salinity. In this study, the influence of $3 \%$ ond $7 \%$ o salinity on pike fry was investigated. High-throughput $16 \mathrm{~S}$ rRNA gene amplicon sequencing was used to profile the gut microbiome of the fish. It was found that salinity had a statistically significant influence on pike fry mortality. Mortality was highest in the 7\%o salinity group and lowest in the 3\%o group. Microbiological analysis indicated that Proteobacteria and Actinobacteria predominated in the pike gut microbiome in all examined groups, followed by lower percentages of Bacteroidetes and Firmicutes. There were no statistically significant differences in the percent abundance of bacterial taxa between the control group and groups with a higher salinity. Our results suggest that salinity influences the gut microbiome structure in pike fry, and that $3 \%$ o salinity may be a good solution for culturing pike at this stage in their development.
\end{abstract}

Keywords: $16 \mathrm{~S}$ rRNA; gastrointestinal tract; gut microbiota; sequencing; salinity; Esox lucius; microbiome; metagenomics

\section{Introduction}

The pike (Esox lucius) is a large, iteroparous, long-lived, top-predator fish species that occupies a broad range of aquatic environments, such as eutrophic and oligotrophic lakes, rivers, and brackish waters [1]. It is a keystone predator that can exert a top-down influence on fish communities [2]. The pike has become an important species for recreational and commercial fishing because of its size, wide distribution, presence in waters in urban areas, and locally high abundance [3-5]. It is also economically important for inland fisheries [6]. The increasing popularity of pike in angling and fish farming has created a need to increase pike fry production [7]. However, intensive pike farming is subject to limitations due to diseases and pathogens.

Although antimicrobial treatments in aquaculture effectively reduce or prevent mortalities caused by primary pathogens, they may have harmful side-effects that affect the overall health of the fish. Chemotherapeutics like antibiotics, vaccines, and immunostimulants can control and prevent disease outbreaks in fish, but these methods can harm both the fish and consumers, by accumulating in fish tissues [8] and causing immunosuppression of the fish and development of microbial resistance to antibiotics. 
In some situations, sodium chloride $(\mathrm{NaCl})$ can be added to tanks to protect fish against pathogens and parasites. $\mathrm{NaCl}$ may be a good alternative for controlling fungal outbreaks and external parasites [9]. In a number of studies, $\mathrm{NaCl}$ has been found to be an effective prophylactic treatment against important protozoans, helminthes, and fungal pathogens [10-12]. Increased salinity helped to suppress trichodiniasis (one of the major diseases in fish aquaculture worldwide, which causes massive fish mortality) in farmed freshwater tilapia (Oreochromis niloticus) [13]. However, changes in salinity can exert stress on fish, and thus affect the growth condition of the animals $[14,15]$. Furthermore, the salinity influences the osmotic gradients between the environment and the animal, which can impair basic physiological processes and even cause death [16].

Pike appear to be able to tolerate some changes in salinity [17-19]. In the Baltic Sea, this predator is found in both estuaries and coastal areas where salinity is at the average level of $3 \%$ ond $7 \%$, respectively $[20,21]$. Therefore, pike might be a good candidate for experiments on the temporary prophylactic addition of $\mathrm{NaCl}$ to tanks, especially at the beginning of the juvenile stage, when the morbidity and mortality are highest. However, although there have been some studies on the effect of salinity on freshwater and marine fish [22-24], including pike [17-19], the studies on pike have focused in physiological changes (body weight and length, immune indicators, and cortisol level). It would be interesting to study how the microbiome can change under the influence of salinity levels that freshwater fish can tolerate. So far, information on the effect of salinity on the pike gut microbiota is lacking.

Information on fish gut microbiota is generally useful for understanding the factors that affect fish health, as research has shown that the gut microbiota play a key role in the health and nutrition of the host [25-27]. Fish gut microbiota contribute to digestion and can affect growth, reproduction, overall population dynamics, and the vulnerability of the host fish to disease [28]. Many studies have reported that the structure of the fish gut microbiota is influenced by factors such as the environment, diet, temperature, and $\mathrm{pH}$ [29-31]. These factors can affect the microbiome by changing the relative abundance of individual groups of microorganisms. Such changes can have repercussions for physiological, hormonal, or cellular functions, which can result in the development of diseases. To date, only a few studies have investigated the effect of salinity on fish gut microbiota [15,32,33]. However, not only were these studies conducted on other species, but even basic information on the pike gut microbiota is lacking.

It seems that this gap in our knowledge should be filled, because information on fish gut microbiota is generally useful in fish domestication [34]. Identification of the gastrointestinal microbiota contributes to our understanding on the functional interactions between microbes and the host [35]. Furthermore, examining the effects of various factors on the structure of the gut microbiome can help to maintain the fish in a good condition by adjusting those factors. For example, feed can be properly composed and enriched with appropriate probiotics and other supplements, and the length and intensity of prophylactic adjustments to salinity can be optimized.

Therefore, the objective of this study was to study the influence of salinity on the composition of the pike gut microbiome. Furthermore, characterization of the gastrointestinal microbiome of pike (E. lucius) using a mass sequencing approach based on genes coding for 16S rRNA was conducted. The differences between the microbiomes of the gastrointestinal tracts of pike from the control tank and tanks with $3 \%$ ond $7 \%$ o salinity levels were investigated. Additionally, we tried to determine if the mortality of juvenile fish in salinity tanks was correlated to changes in the microbiome. Information concerning the influence of salinity on the fish gut microbiome may help to develop our understanding on the functions of the fish gut microbiota, provide insight into growth condition differences, and explain the influence of salinity on host nutrition and/or physiology. 


\section{Materials and Methods}

\subsection{Conditions of Fish Rearing}

The fish were cultured at the Department of Lake and River Fisheries, University of Warmia and Mazury in Olsztyn, Poland. The experiment was conducted in rectangular glass aquarium tanks with a capacity of $25 \mathrm{dm}^{3}$. Experimental groups of fish were kept in salinity levels of 3\%o and 7\%o, obtained by adding $\mathrm{NaCl}$ to tap freshwater in proper amounts. The control group of fish was kept in a freshwater tank. The experiment was conducted by producing two replicates per group of treatment. Each tank had a filter and its own water pump with a separated water cycle. The fish density in the aquarium was $10 \mathrm{fish} / \mathrm{dm}^{3}$. During the experiment, the water temperature was $15^{\circ} \mathrm{C}$. The fish were fed with commercial Artemia Premium Cysts three times per day, with the amount depending on the number of fish in the tank. The experiment lasted for 10 days, which is a typical period of time for fry pike rearing. During the experiment, the mortality of fish in each tank was counted daily. Each day of the experiment, fish in all tanks were observed. At the end of each day, dead fish were noted and removed from tanks.

An ethics statement is not required for this type of research. No specific permissions were required for the described studies. The studies did not involve endangered or protected species. All experimental procedures were conducted in accordance with Polish law.

\subsection{Sampling}

At the end of the experiment, pike were randomly chosen from the control group (group TS_0\%o) and two studied groups (TS_3\%o and TS_7\%o). To obtain the morphological parameters, 20 random fish from each group were weighted and measured. Length and weight measurements were also used to calculate the body condition index (BCI; defined as weight/length ${ }^{3}$ ) as an indicator of the overall physiological state [36] and compared among salinity treatments over time. For microbiological analyses, 30 fish were analyzed (10 fish from each salinity group). To sacrifice each fish, MS-222 $\left(150 \mathrm{mg} / \mathrm{dm}^{3}\right)$ was used. To remove excess mucus from the ventral body surface, it was wiped with a paper towel. Then, to sanitize all instruments and surfaces, and the exterior of each fish, they were treated with $70 \%$ ethanol, after which, the instruments were flame-sterilized for dissection. For the removal of any remaining ethanol, the ventral body surface was dried with a paper towel. Next, the body cavity was opened and the entire gastrointestinal tract and its contents were aseptically removed from each fish. After this, the guts and their contents were stored at $-20^{\circ} \mathrm{C}$ until analysis.

\subsection{DNA Extraction}

For DNA isolation, the entire fish gut and its contents were used. Plastic spatulas were used to homogenize samples. DNA was then extracted using a QIAmp DNA Stool Mini Kit (Qiagen, Hilden, Germany), according to the manufacturer's instructions. To quantify DNA, a Qubit 2.0 Fluorometer (Invitrogen, Carlsbad, CA, USA) was used. For verification of the DNA integrity, $1 \%$ agarose gel electrophoresis was performed. Purified DNA was suspended in $60 \mu \mathrm{L}$ of elution buffer and then stored at $-20^{\circ} \mathrm{C}$.

\section{4. $16 \mathrm{~S}$ rRNA Gene Amplicon Library Preparation and Sequencing}

To verify the quality and bacterial origin of DNA, PCR was performed with two universal $16 \mathrm{~S}$ rRNA primers: $8 \mathrm{~F}$ and 534R [37]. Based on these results, the DNA yield, and quality, 20 samples were chosen (seven from both TS_0\%o and TS_7\%o, and six from TS_3\%o) and sent to Genomed S.A (Poland) for the mass sequencing of 16S rRNA amplicons. To prepare the 16S rRNA gene amplicons, the Illumina protocol "16S Metagenomic Sequencing Library Preparation" was used. In the PCR reaction, the variable V3 and V4 regions of the $16 \mathrm{~S}$ rRNA gene were amplified using the following primers: forward (5' CCTACGGGNGGCWGCAG $3^{\prime}$ ) and reverse (5' GACTACHVGGTATCTAATCC $3^{\prime}$ ) [38]. The reaction was performed according to the Illumina protocol. To index the amplicons, a Nextera ${ }^{\circledR}$ XTIndex 
Kit (Illumina, San Diego, CA, USA) was used according to the producer's instructions. For DNA sequencing, an Illumina MiSeq instrument was used, employing a $2 \times 250$ paired-end protocol, along with a Miseq reagent kit v3 (Illumina, USA).

\subsection{Microbiome Analysis}

To process raw paired-end sequences (1,809,106 reads from 20 samples), the QIIME 2 [39] software package (https://qiime2.org; version: 2018.8) was employed. Paired ends were merged, reducing the 1,809,106 reads to $1,533,836$ reads, and reads that could not be merged were excluded from further analyses. For quality control of the sequences, the Deblur plugin in Qiime 2 [40] was used to associate erroneous sequence reads with the true biological sequence from which they were derived, thus producing high-quality sequence variant data. First, 213,390 reads (13.91\% of the data) were removed by applying an initial filtering process quality score $(q=20)$. Second, using Deblur, all reads were trimmed to $285 \mathrm{bp}$, based on the median quality score. In addition, chimeric sequences were detected and excluded from analyses. 16S rRNA Operational Taxonomic Units (OTUs) were picked from the Illumina reads using a closed-reference OTU picking protocol against the Greengenes database (https://docs.qiime2.org/2018.8/data-resources; data files: 13_8) clustered at 99\% identity and trimmed to span only the $16 \mathrm{~S}$ rRNA V4 region flanked by sequencing primers 515F-806R. In the next step, taxonomy assignments were associated with OTUs based on the taxonomy associated with the Greengenes reference sequence defining each OTU. This step discarded most of reads which were not found in the Greengenes database and found only 228,667 reads which were assigned taxonomy. Out of the 228,667 Illumina reads from the V4 region of the bacterial 16S rRNA genes that passed the QIIME quality filters, $90.6 \%$ (207,197 reads) matched a reference sequence at a $99 \%$ nucleotide sequence identity. Next, OTU counts were binned into genus-level taxonomic groups for plot preparation.

Sequencing data were exported as individual fastq files and have been deposited in the Sequence Read Archive (SRA) NCBI (https://www.ncbi.nlm.nih.gov/) under the accession no. SRP226690. Samples can be found under accession numbers from SRX7043689 to SRX7043708.

\subsection{Statistical Analysis}

Alpha and beta diversity statistics were recorded using the QIIME 2 scripts diversity plugin, which supports metrics for calculating and exploring the community alpha and beta diversity through statistics and visualizations in the context of sample metadata. In the calculation of alpha diversity metrics, normalization was performed using the "rarefaction" QIIME 2 process with standard parameters, setting the max_rare_depth (upper limit of rarefaction depths) to the mean sample size. Alpha diversity metrics were calculated using 'observed species', 'Chao1 index' (species richness estimator), 'Shannon's diversity index', and 'Good's coverage'. An alpha-rarefaction plot was created for each metric. The alpha diversity values at the same rarefaction level were calculated.

The normality and homogeneity of variance of all weight, length, and alpha diversity indices obtained from fish gut microbiome analysis were checked by Shapiro-Wilk's and Levene's test. Next, one-way ANOVA followed by Tukey-Kramer's post-hoc test $(p=0.05)$ was used to check the statistical differences between fish of different tanks (STATISTICA v.13.1 (StatSoft, Inc, Tulsa, OK, USA)).

The number of reads across samples was normalized by the sample size and the relative abundance (\%) of each taxon was calculated. All taxa found in the gut microbiome were considered for statistical analysis. Statistical analysis of intestinal microbial profiles was performed using the Statistical Analysis of Metagenomics Profiles (STAMP) program (http://kiwi.cs.dal.ca/Software/STAMP), retaining unclassified reads [41]. To conduct a reliable statistical analysis, one sample (from TS_0\%o) was rejected from the analysis due to the low number of reads assigned to taxon levels. All $p$-values were calculated by ANOVA followed by Tukey-Kramer's post-hoc test and corrected for multiple comparisons using the Benjamini-Hochberg method for a False Discovery Rate (FDR) of 5\% [42].

The beta diversity metric is an estimation of the between-sample diversity of the microbial profile and it was calculated by the QIIME 2 "diversity beta-group-significance" script. Both weighted 
(abundance matrix) and unweighted (presence/absence matrix) UniFrac distances [43,44] were used. The distance matrices were graphically visualized by three-dimensional principal coordinates analysis (PCoA) representations.

Differences in the beta diversity of bacterial communities were verified using a nonparametric Permutational Multivariate Analysis of Variance (PERMANOVA) test with 999 permutations ( $p=0.05$ ). A pairwise significance test was also performed by comparing groups from tanks with different salinity levels using the same distance matrix metrics (weighted and unweighted UniFrac distances). These tests were available in QIIME 2.

\section{Results}

\subsection{Fish Culturing}

Fish mortality was observed in all tanks during the experiment. The number of dead fish was noted and used to prepare the cumulative mortality of fish plot (Figure 1). The lowest mortality was observed in tanks with $0 \%$ ond $3 \%$ o salinity, representing less than $6 \%$ of the cumulative mortality at the end of the experiment. In the TS_7\%o group, mortality increased more intensively and reached 37\% at the end of the experiment. At the end of the experiment, the weight and length of fish from each tank $(n=20)$ were measured (Figure 2A). The length and weight were used to calculate the BCI and were presented on a plot (Figure 2B). Statistical analysis showed significant differences in both the length and weight between different salinity groups.

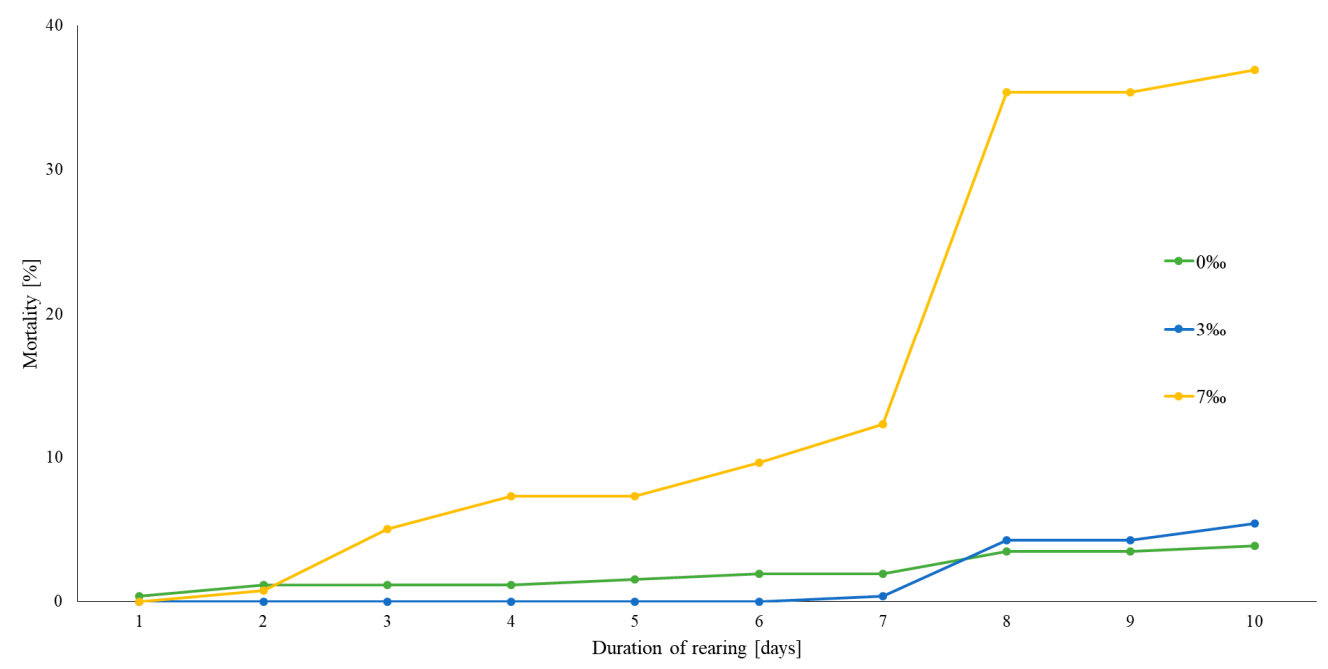

Figure 1. Cumulative mortality of pike fry during 10 days of the experiment. The experiment was conducted in rectangular glass aquarium tanks with a capacity of $25 \mathrm{dm}^{3}$ ( $\mathrm{n}=2$ per each group). Each tank had a filter and its own water pump with a separated water cycle. The density of fish in the aquarium was $10 \mathrm{fish} / \mathrm{dm}^{3}$ and the water temperature was $15^{\circ} \mathrm{C}$. The fish were fed with commercial Artemia Premium Cysts three times per day. 

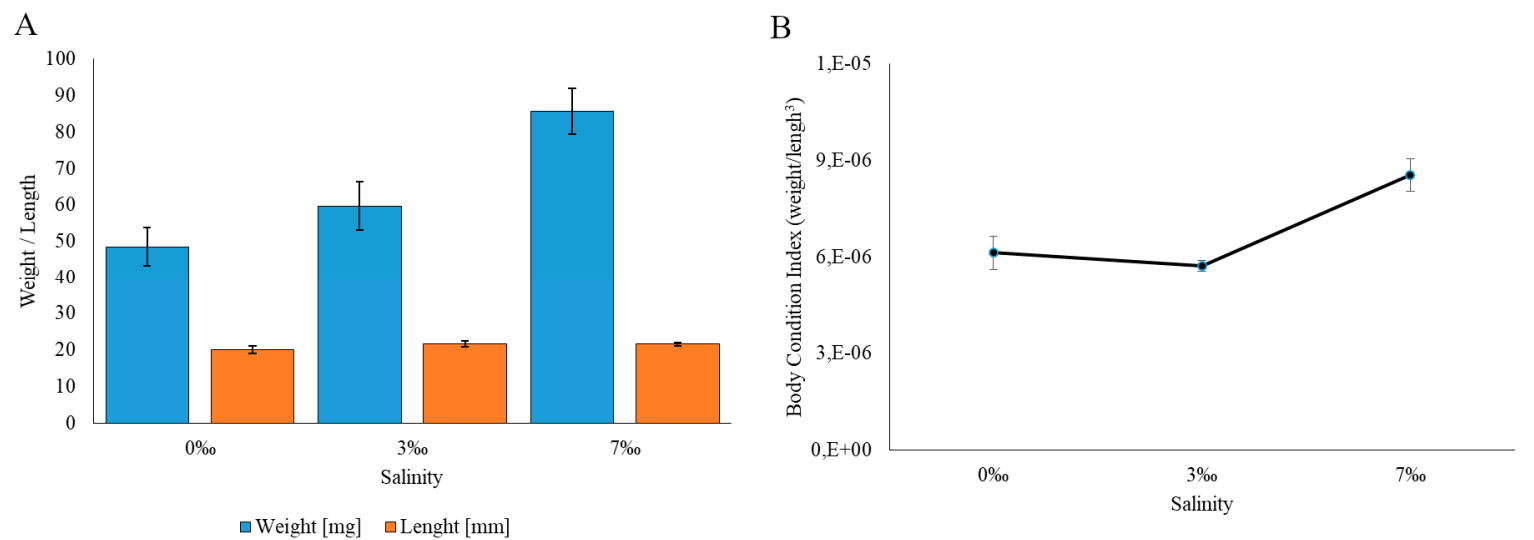

Figure 2. (A) Average weight and length of fish at the end of the experiment ( $n=20 /$ group) and (B) the effects of salinity on the pike condition index $=$ weight $(\mathrm{g}) /$ fork length $(\mathrm{mm})^{3}$; the mean \pm SEM for each salinity level $(n=20)$.

\subsection{Qiime Analysis of Sequencing Data}

The fastq files with data on the gut microbiome of 20 chosen fish obtained from the Illumina MiSeq were analyzed using QIIME 2 software. After filtering for quality, trimming length, and assigned taxonomies, the number of reads taxonomically classified according to the Greengenes database was 207,197 (Table 1). This value corresponded to an average number of 10,360 per sample (range 4260-17,585). A total of 937 OTUs at a $99 \%$ nucleotide sequence identity in pike gut content samples were identified. After rarefaction, which normalized the sample to the max rare depth of sequences, the observed species number per sample was between 93 and 235, corresponding to an average number of counts per group between 140 and 196 (Table 1). Good's coverage values for all groups were $\geq 0.99$, indicating that sequencing coverage was attained and that the OTUs found in the samples were representative of the sampled population (Table 1). All the rarefaction curves tended to plateau (Figure S1). By statistically analyzing the OTU index of the examined groups, it was found that salinity was a factor which affected the species richness. As for the rest of the indices, salinity was not a factor with a significant affect.

Table 1. Mean number of reads per sample assigned to OTUs, and alpha diversity metric values (without one sample with less than 737 reads) of the gut microbial community of pike from different environments.

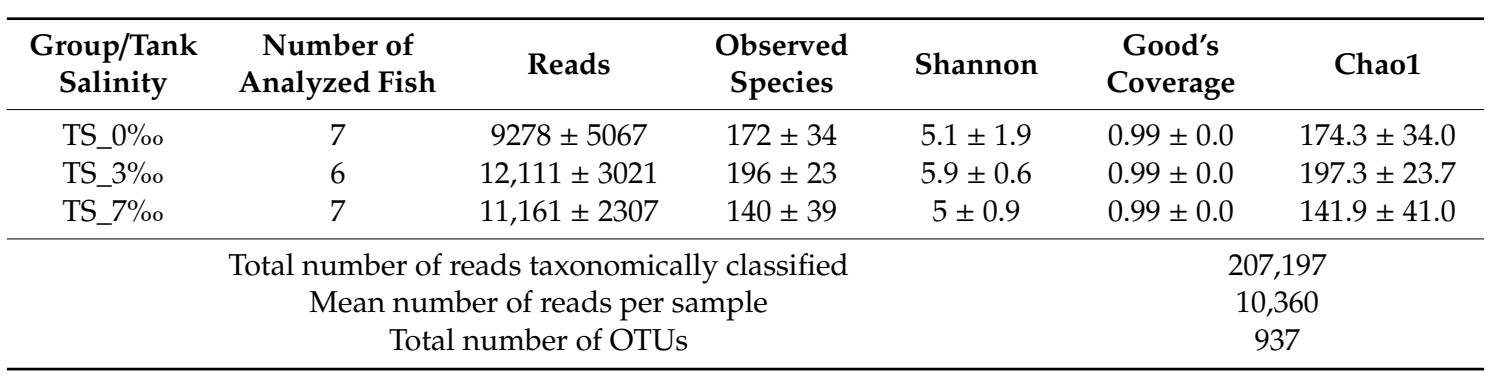

\subsection{Characterization of the Pike Gut Microbiome}

The gut microbiome of 20 fish in three groups that were kept at different levels of salinity was examined to characterize its structure and to reveal the differences between groups and individual fish. The microbiome structures of each investigated group of fish at the phylum, class, order, and family level were successfully described. In our study, 15 phyla, 32 classes, 53 orders, and 88 families were classified. The gut microbial community in the groups as a whole and in individual fish are presented at the phylum (Figure 3), class (Figure 4), and order (Figure 5) levels. The figures present taxa with a 
relative abundance $\geq 0.5 \%$ (up to the class level) and $\geq 2.5 \%$ at the order level. All taxa are shown in Table S1.
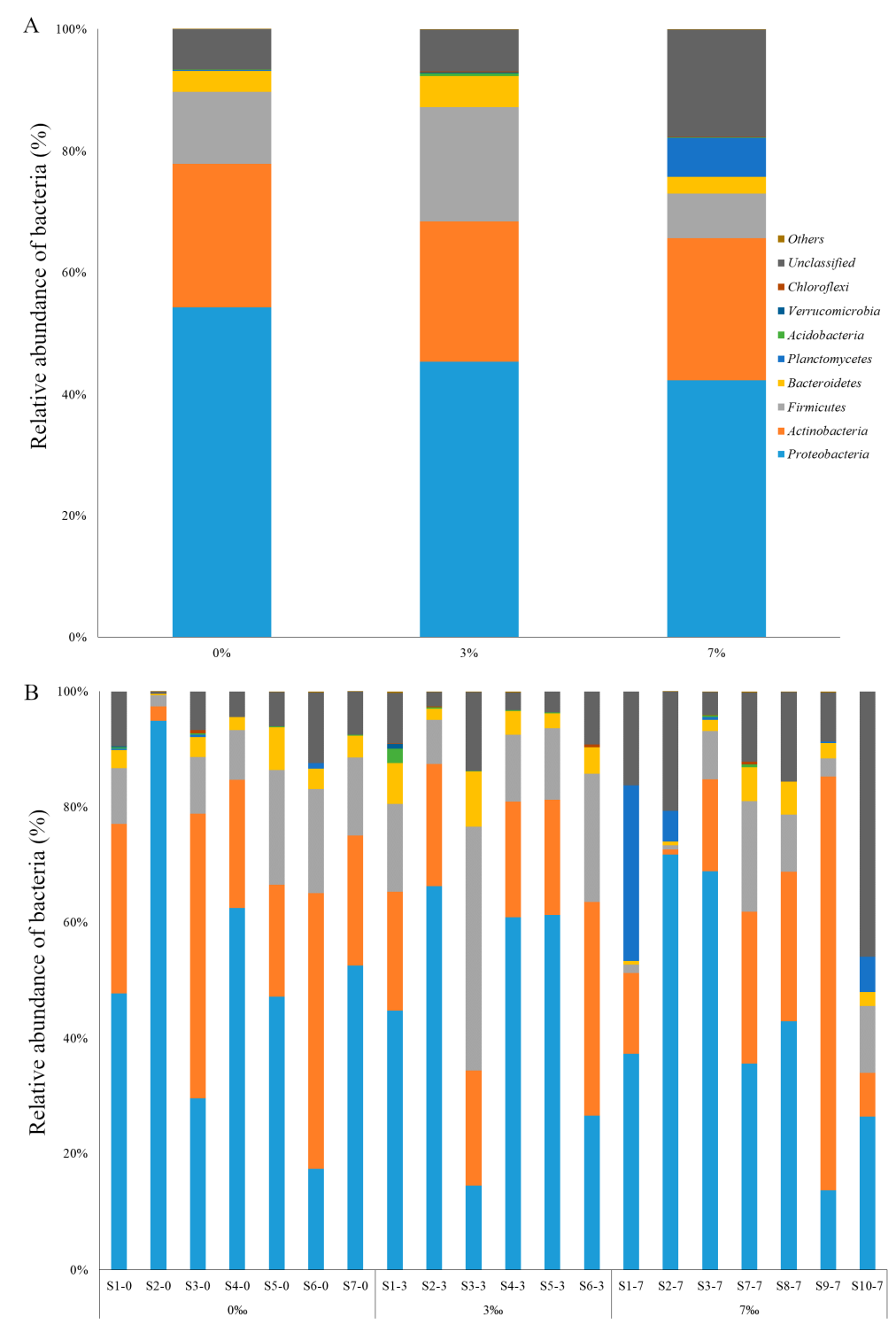

Figure 3. Relative abundance (\%) of the most prevalent bacterial phyla in three groups kept at different levels of salinity (A) and in individual pike (B). Figures show all phyla with an abundance $>0.5 \%$. Phyla with an abundance $\leq 0.5 \%$ are pooled and labeled as "Others". 

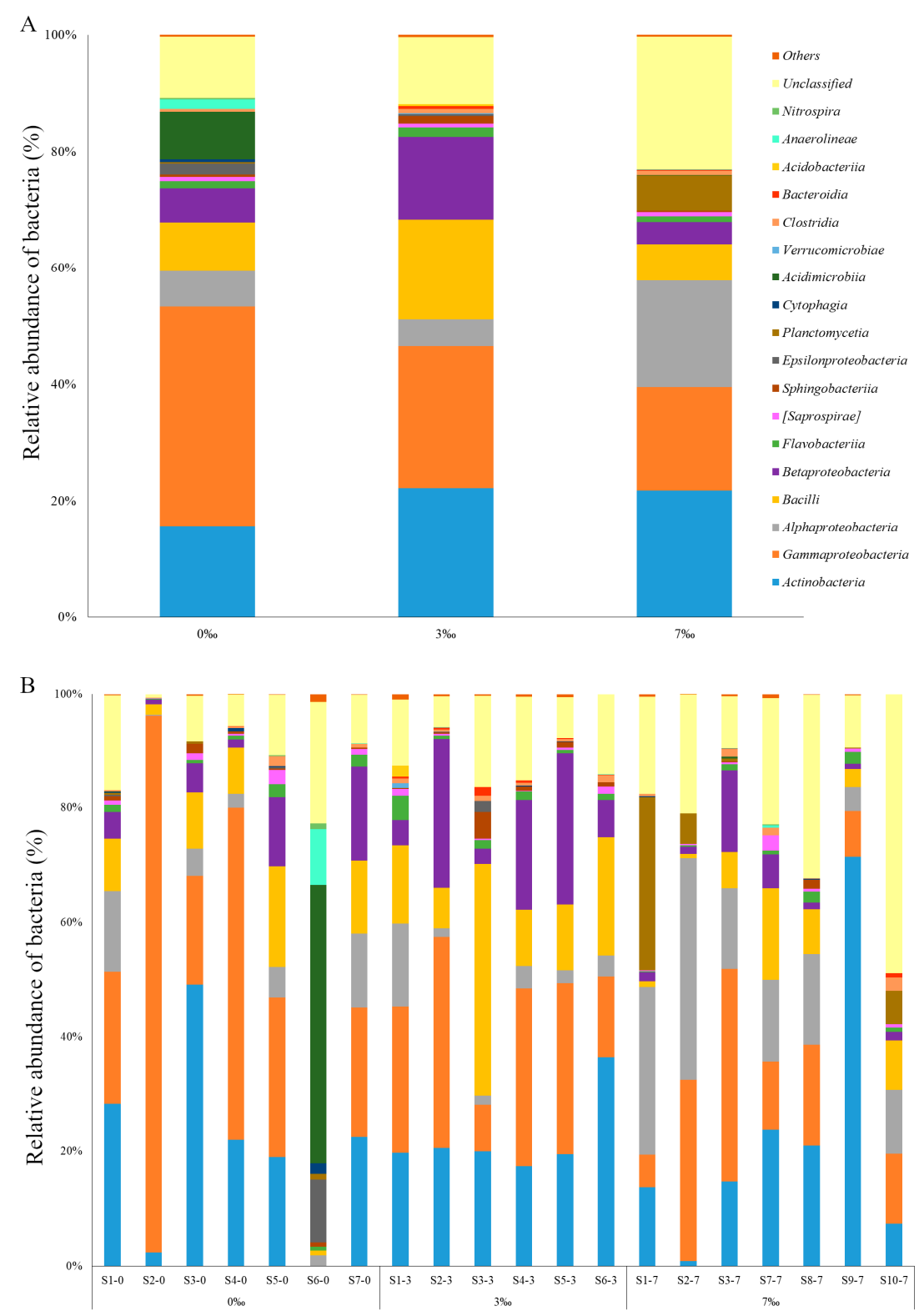

Figure 4. Relative abundance (\%) of the most prevalent bacterial classes in three groups kept at different levels of salinity (A) and in individual pike (B). Figures show all classes with an abundance $>0.5 \%$. Classes with an abundance $\leq 0.5 \%$ are pooled and labeled as "Others". 

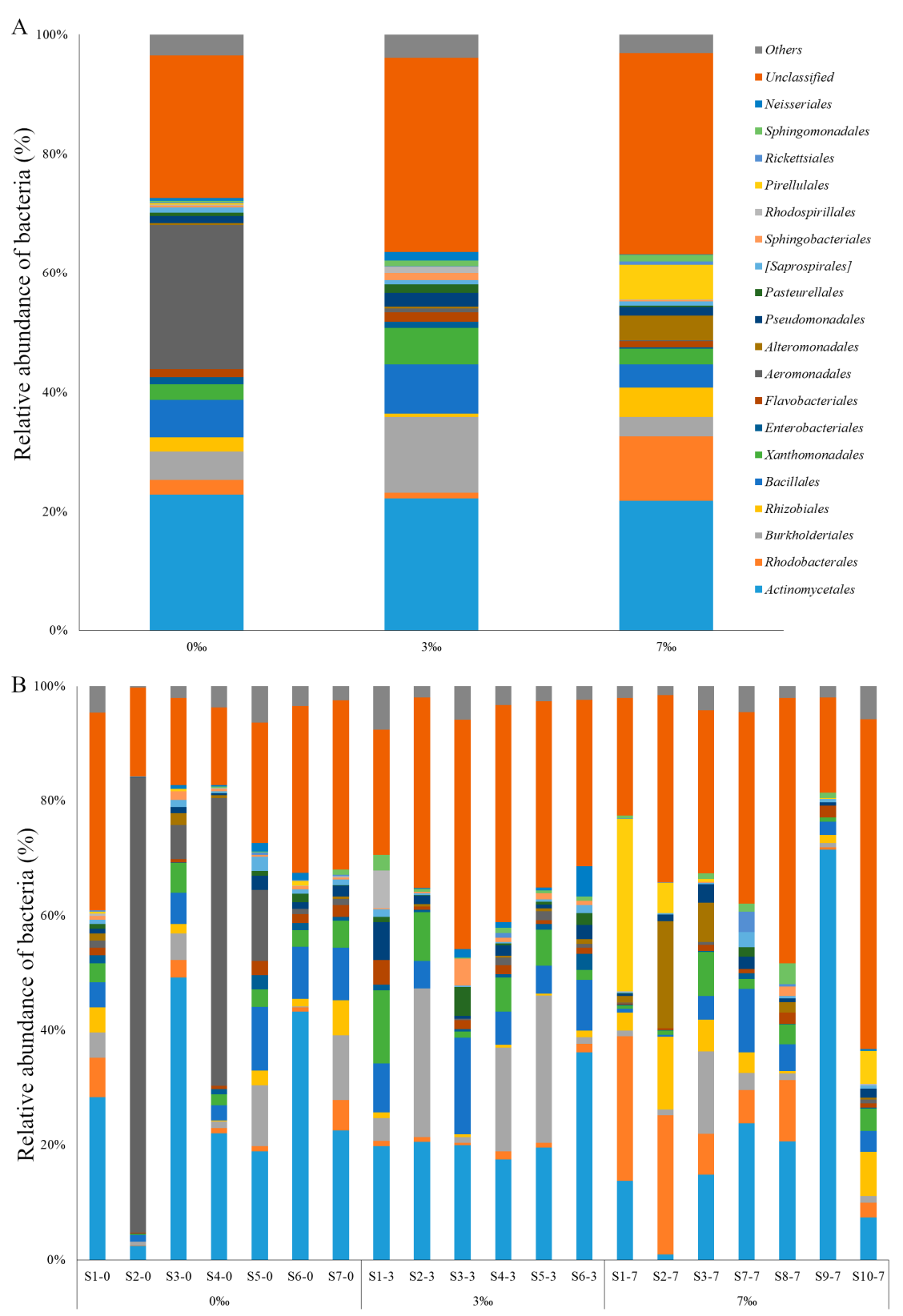

Figure 5. Relative abundance (\%) of the most prevalent bacterial orders in three groups kept at different levels of salinity (A) and in individual pike (B). Figures show all orders with an abundance $>2.5 \%$. Orders with an abundance $\leq 2.5 \%$ are pooled and labeled as "Others".

At the phylum level, Proteobacteria predominated in each group (mean abundance of $40 \%-53 \%$ ), followed by Actinobacteria, Firmicutes, and Bacteroidetes (Figure 3A, Table S1). In individual fish, the composition of the bacterial community was generally similar to that in the groups as a whole, with four exceptions. In fish S3-3, Firmicutes predominated (42.7\%) (Figure 3B), whereas in fish S3-0, S6-0, and S9-7, Actinobacteria predominated (43\%-72\%). Interestingly, in the $7 \%$ o salinity group, Planctomycetes were more abundant in three fish than in the other fish $(5.3 \%-30.2 \%$ vs. $\leq 0.5 \%)$

At the class level, in almost all fish in the investigated groups, the gut microbiome was dominated by members of Gammaproteobacteria $(17.7 \%-37.5 \%)$ and Actionobacteria $(15.6 \%-22.2 \%)$ (Figure $4 \mathrm{~A}$, Table S1). Alphaproteobacteria were third in terms of the percent abundance in all groups. Some of the gut microbiome profiles of individual fish were different from those of other individuals. For example, the gut microbiome of fish S6-0 was dominated by Acidimicrobiia (48.64\%), whereas in 
other fish, its abundance was less or even absent (Figure 4B). The gut microbiome of fish S3-0 was completely dominated by Gammaproteobacteria (93.8\%), whereas in fish S9-7, the gut was dominated by Actionobacteria $(71.4 \%)$. Bacili dominated the gut microbiome of fish S3-3 (40.6\%), whereas Alphaproteobacteria dominated that of fish S2-7.

At the order level, a higher percent abundance of unclassified bacteria (23.8-33.7\%) was observed than at higher taxonomic levels. In all groups, there was a similar predominance of Actinomycetales $(21.8 \%-22.8 \%)$ (Figure 5A). In TS_7\%o, the mean abundance of Rhodobacterales was greater $(10.84 \%)$ than in the rest of the groups $(0.97 \%-2.44 \%)$. Burkholderiales were present in all groups, but more abundant in TS_3\%o (12.66\%) (Figure 5A). The bacterial community composition of the gut of an individual fish tended to be more similar to that of other fish in the same group than to that of fish in other groups. Rhodobacterales were present in all fish microbiomes, but in TS_7\%o, they were more abundant in five fish (5.8\%-25.2\%) (Figure 5B). Interestingly, in the 3\%o salinity group, Aeromonadales were more abundant in four fish than in the other fish $(5.97 \%-79.4 \%$ vs. $\leq 1.57 \%)$.

One-way ANOVA was calculated and differences were considered significant at $p<0.05$ after Benjamini-Hochberg FDR correction for multiple comparisons. In addition, the corresponding effect size (ETA-Squared) was calculated. This analysis showed no statistically significant differences between groups in terms of the abundance of each taxa of bacteria. Statistical analyses of all taxa and their relative abundance (\%) are reported in Table S1. Although any significant differences in relative abundance (\%) of all taxa between groups were not found, it is interesting to note that the abundance of some bacteria was higher for specific salinity concentrations in most of the fish gut microbiome group. At 7\%o salinity, Planctomycetes, Rhodobacterales, and Alphaproteobacteria were more abundant than at other levels of salinity; at 3\%o, in contrast, Betaproteobacteria and Burholderiales were more abundant; and in the control tanks, Aeromonadales were more abundant (Table S1).

Permutation multivariate analysis (PERMANOVA) indicated that, overall, there was a significant divergence between groups only in terms of unweighted UniFrac distance matrices $(p=0.001$; Pseudo-F $=1.63$ ) (Table 2). The beta-diversity pairwise test on the unweighted UniFrac data showed that the gut microbiomes of fish in $7 \%$ o salinity were significantly different to those of the $3 \%$ o salinity group. Weighted Unifrac did not show a significant overall difference in the abundance of bacteria.

Table 2. Permutation multivariate analysis (PERMANOVA) of weighted and unweighted Unifrac data of intestinal microbiomes of pike living in different environments.

\begin{tabular}{ccccc}
\hline \multirow{2}{*}{ PERMANOVA Analysis } & \multicolumn{2}{c}{ Unweighted Unifrac } & \multicolumn{2}{c}{ Weighted Unifrac } \\
\cline { 2 - 5 } & $p$-Value & Pseudo-F & $p$-Value & Pseudo-F \\
\hline One-way & & & & \\
All groups & 0.001 & 1.63 & 0.052 & 1.69 \\
\hline PERMANOVA pairwise test: & & & & \\
0\%o vs. 3\%o & 0.002 & & 0.241 & \\
0\%o vs. 7\%o & 0.137 & 0.146 & \\
3\%o vs. 7\%o & 0.001 & 0.031 & \\
\hline
\end{tabular}

QIIME 2 was used to compute microbial beta diversity metrics. Analyses were performed using weighted and unweighted UniFrac distances. Data from UniFrac metrics were used to prepare three-dimensional plots using principal coordinates analysis (PCoA) (Figure 6). PCoA reflected the PERMANOVA results. Weighted Unifrac showed that the $0 \%$ and $3 \%$ salinity groups clustered together. Fish from 7\%o salinity were separated from the rest of the samples. PCoA of the unweighted Unifrac distance matrix showed that samples from the 3\%o salinity group clustered together and samples from the other groups were scattered. 


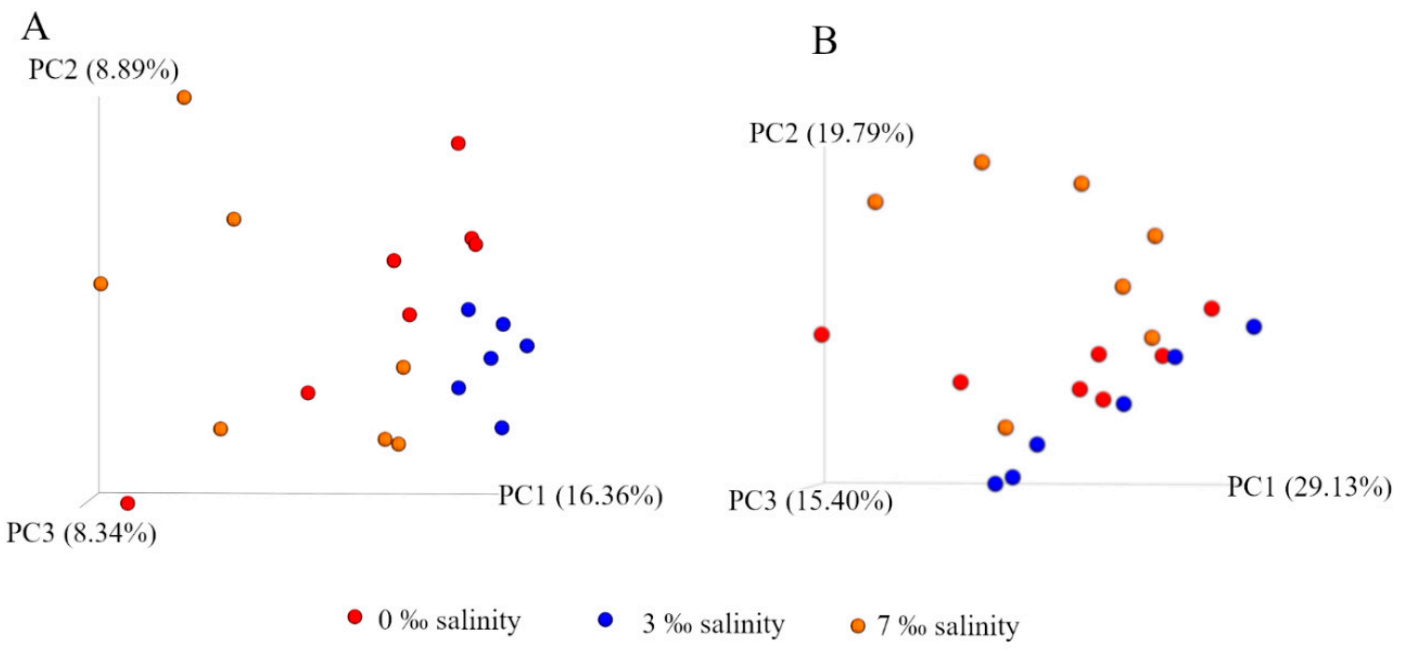

Figure 6. Beta diversity metrics. Principal coordinates analysis (PCoA) of unweighted (A) and weighted (B) Unifrac distances of gut microbial communities associated with different salinity levels. The figures show plots of individual fish according to their microbial profile.

\section{Discussion}

Recent studies on the effect of salinity on fish have focused on examining how salinity affects the growth, mortality, health condition, and osmotic stress of fish farm $[9,13,14,22,45,46]$ and hatching eggs [47]. This type of research is necessary because it might help to properly choose salt concentrations and times of exposition of fish to keep them healthy during farming. Salt is commonly used as a disinfectant for the prophylactic prevention of disease development in fish farms, and thus might help to keep fish in good health, especially at the beginning of fish fry life. It is a cheaper, and probably healthier, replacement for other chemotherapeutics. However, the effect of salinity on the fish gut microbiome has been poorly investigated. Although there have been studies on the effect of salinity on the gastrointestinal microbiome of a few fish species [15,32,33,48], to the best of our knowledge, there is a lack of studies on the gut microbiome of pike fry (E. lucius). Therefore, it was hypothesized that the gut microbiota of pike living in freshwater differ from those of pike living in different salinity concentrations. What is more, a comparison of the morphological parameters and mortality of fish under osmotic stress was conducted. Our results provide information on the gut microbiota of pike and highlight associations between environmental factors (salinity) and gut microbiota. An understanding of these associations provides information that may be useful for addressing problems during the domestication of these valuable freshwater fish.

In our study, the size and weight of pike fry were influenced by long-term salinity tolerance. All examined fish reached a developmental stage where the organs involved in osmoregulation, e.g., the gills, were expected to be fully functional. Although the average length of fish showed little difference between each tank, the mean weight differed to a greater extent (Figure 2A). Generally, along with increasing the salinity, the environment should be cleaner and healthier, which could prevent the excessive development of pathogens, leading to better welfare of animals. However, in our study, the highest growth of fish from the 7\%o group was related to the lowest density of fish caused by the highest mortality. In these conditions, high-salinity fish had better access to food, and thus showed the highest weight values.

Mortality is a common problem in fish fry farms due to diseases mainly caused by pathogens [49]. Salt used in farming freshwater fish which tolerate some salinity is quite effective, cheaper, and much healthier (for fish and consumers). Sometimes, in aquaculture, fish are bathed prophylactically in brine to avoid pathogen development [50]. Our results showed that salinity had a statistically significant effect on cumulative mortality in fish. The greatest mortality was observed in the $7 \%$ o salinity tank, increasing drastically on day 8 of the experiment to about 37\% (Figure 1). Here, the length of the fish 
was the greatest. It seems that larger pike fry cannot acclimate to these long-term osmotic conditions. This is in good agreement with other studies on pike, where the mortality of larger fish was greater than that of smaller fish [18]. The cumulative mortality of fish from tanks with a 3\%o salinity was surprisingly similar to that of the control group. What is more, the BCI was greater than in the control group. These findings suggest that this level of salinity is well-tolerated by pike, which is consistent with reports of this species in coastal areas all around the Baltic Sea, where salinities vary from $4 \%$ o to $7 \%$ [18]. The fact that around $97 \%$ of fish survived this salinity treatment and had a condition factor similar to that of the controls indicates that the fish in 3\%o salinity did not experience a loss of water due to salinity stress. A loss of water is believed to be one of the reasons why fish have died in salinity treatments [18].

Our study indicated that, in the pike gut microbiome, the phyla Proteobacteria and Actinobacteria predominate, followed by lower percentages of Bacteroidetes and Firmicutes (Figure 3), in both control fish and fish in different salinity levels. This observation suggests that these phyla could play important roles in pike gut functioning. Although it is difficult to estimate the contribution of specific bacteria to the function of the whole gut ecosystem, it is reasonable to expect that the overall gut microbiome will be strongly influenced by the predominant microorganisms [28]. The presence of similar bacterial taxa in the gut microbiota of multiple fish species suggests that these bacteria are valuable for the host and could play important roles in digestion, nutrient absorption, and immune responses [51]. These phyla have been found in the intestines of many marine and freshwater fish species [52-56]. However, the proportions of these phyla present in our study were different to those in other studies [33,57,58]. In studies on eight freshwater fish species [55], marine Atlantic cod [59], and Fine flounder [60], Proteobacteria has been described as the predominant phylum. On the other hand, Firmicutes predominate in the intestinal content of aquacultured Siberian sturgeon [61], grass carp [62], and Atlantic salmon [63]. Our study showed that the mean abundance of Proteobacteria of a group might be a predominant phylum (Figure 3A). However, looking at individual fish, the proportions of the percent abundance of main phyla were not similar. Sometimes, Actinobacteria predominate over Proteobacteria. This observation was noticed in control and salinity tanks, so salinity does not have a significant influence on the gut structure at the phylum level. This may be related to fish development. It appears that the diversity of bacteria increases as fish develop [64]. Ringø and Birkbeck [65], in their review, summarized 24 studies on the microbiome of fish larvae and fry and showed changes during fish development. Furthermore, relatively stable gut microbiota are established within the first 50 days of life for many species [66]. Therefore, gut microbiota of pike might just have been forming during the experiment. Despite these facts, our results suggest that Proteobacteria, Firmicutes, Bacteroidetes, and Actinobacteria, which dominate in the fish gut, may play important roles in the gut microbiome of pike at an early life stage.

Various salinity concentrations can lead to osmotic stress in fish. Physiological changes in the host that occur during osmotic stress force its gut microbiome to adapt to the new conditions. Therefore, new species may develop in the gut microbiome. Although significant differences in the abundance of taxa between control and salinity groups (Table S1) were not found, there were small changes in the percent abundance of some groups. In some fish reared in 7\%o salinity, a higher percent abundance of Planctomycetes were observed, whereas in the other groups, these bacteria were absent. Planctomycetes were found in yellow grouper, which is a marine fish [67]. Another study reported that Planctomycetes were found in macroalgae biofilm [68]. This suggests that Planctomycetes like salty environments and could multiply under the influence of this stress factor.

In most fish, at all salinity concentrations, Proteobacteria usually predominate over other phyla. In contrast to our results, a study on Oreochromis niloticus (Nile tilapia) showed that the percent abundance of Proteobacteria changed and was higher in fish from a marine environment than in those from a freshwater environment [15]. Furthermore, the study found that Actinobacteria and Bacteroidetes were more abundant in fish from freshwater than in those from marine water, whereas our study found similar levels of these phyla at all salinity levels. The reason for these results is not yet completely 
understood, but the results might depend on many conditions, such as the salinity concentration, fish species, length of exposition, diet, age of the fish, and others. Although significant changes in phyla were not observed, differences in the percent abundance of Proteobacteria classes between salinity levels were observed. Alphaproteobacteria predominated in 7\%o salinity, whereas in 3\%o and control tanks, Betaproteobacteria were more abundant. An effect of salinity on the microbiome structure was also found in black molly (Poecilia sphenops), where an increase in salinity induced changes in the dominant bacterial taxa in the microbiomes [32]. In the more saline treatments in their study, unknown Enterobacteriaceae (18\%o and 30\%o) replaced Aeromonas and Cetobacterium OTUs that were present in the freshwater treatments ( $0 \%$ ond $5 \%$ o). Although their results differ slightly from our results, they confirm that salinity can influence the gut microbiome. Furthermore, it is interesting to note that Aeromonadales, which was more abundant in control fish in our study, was less abundant in fish with salinity treatment. This supports previous findings in other studies [33,34], where microbes differ on broader scales between freshwater and saltwater fish, with the bacteria Aeromonadales being enriched in freshwater specimens and anadromous fish collected from freshwater habitats. Those researchers also found that Vibrio exhibited a greater prevalence in marine species. Although an increased percent abundance of Vibrio in fish with 3\%o and 7\%o salinity was not observed in our study, Burholderiales was more abundant in 3\%o salinity, and Rhodobacterales was more abundant in 7\%o salinity. However, it is necessary to note that, in the cited studies [33,34], different fish from freshwater or marine water were studied, so it is difficult to evaluate the exact role of salinity in shaping the intestinal microbiota. In contrast, our study focused on one species in different conditions and suggests that the gut microbiota composition is related to salinity.

\section{Conclusions}

In conclusion, our research provides the first detailed description of the structure of the gut microbiome of juvenile pike (E. lucius). The dominant phyla were Proteobacteria and Actinobacteria, followed by lower percentages of Bacteroidetes and Firmicutes. These phyla are the main components of the gut microbiome in many other fish species $[56,65]$. Despite the fact that there were no significant differences in the percent abundance of gut bacteria species, some taxa were more abundant at certain levels of salinity. At 7\%o salinity, Planctomycetes, Rhodobacterales, and Alphaproteobacteria were more abundant than at other levels of salinity; at 3\%o, in contrast, Betaproteobacteria and Burholderiales were more abundant; and in the control tanks, Aeromonadales were more abundant. Furthermore, the alpha diversity based on the OTU index showed that salinity affected the number of species. Taken together, these findings indicate that salinity influences the bacterial biodiversity. Our results also suggest that salinity influences the composition of the pike gut microbiome in terms of the percent abundance of bacteria. At 3\%o salinity, mortality was low (similar to that in the control tanks), suggesting that this concentration is tolerated by the pike, beneficial for their development, and protects them from pathogens at an early life stage. Our findings suggest that salinity adjustment can improve fish welfare and aquaculture practices. To test this hypothesis, future interspecific studies should test a wider range of salinity levels and include long-term exposition.

Supplementary Materials: The following are available online at http://www.mdpi.com/2076-3417/10/7/2506/s1: Figure S1: Alpha diversity metrics. Rarefraction curves of the gut microbiome structure from pike kept at different levels of salinity. (A) Observed OTU's, (B) species richness (Chao1), and (C) Shannon's diversity index; Table S1: Statistical analysis of the mean relative abundance $(\%) \pm$ SD of phyla, classes, orders, and families between groups.

Author Contributions: Conceptualization, S.C. and T.D.; methodology, T.D. and S.C.; software, T.D.; validation, T.D.; formal analysis, T.D. and M.G.; investigation, T.D.; resources, R.K.; data curation, T.D.; writing-original draft preparation, T.D.; writing-review and editing, T.D., S.C., R.K., and M.G.; visualization, T.D.; supervision, S.C.; project administration, S.C. and T.D. All authors have read and agreed to the published version of the manuscript.

Funding: The project was financed as part of a grant statutory project (No. 29.610.024-110) of the University of Warmia and Mazury in Olsztyn and financially co-supported by the Minister of Science and Higher Education in the scope of the program entitled "Regional lnitiative of Excellence" for the years 2019-2022, Project No. 010/RID/2018/19, amount of funding 12.000.000 PLN. 
Conflicts of Interest: The authors declare no conflicts of interest.

\section{References}

1. Forsman, A.; Tibblin, P.; Berggren, H.; Nordahl, O.; Koch-Schmidt, P.; Larsson, P. Pike Esox lucius as an emerging model organism for studies in ecology and evolutionary biology: A review: Esox lucius as a model in ecology and evolution. J. Fish Biol. 2015, 87, 472-479. [CrossRef] [PubMed]

2. Craig, J.F. Pike: Biology and Exploitation; Springer: Dordrecht, The Netherlands, 1996; ISBN 978-94-015-8775-4.

3. Pierce, R.B.; Tomcko, C.M.; Schupp, D.H. Exploitation of Northern Pike in Seven Small North-Central Minnesota Lakes. N. Am. J. Fish. Manag. 1995, 15, 601-609. [CrossRef]

4. Arlinghaus, R.; Mehner, T. A Management-Orientated Comparative Analysis of Urban and Rural Anglers Living in a Metropolis (Berlin, Germany). Environ. Manag. 2004, 33, 331-344. [CrossRef] [PubMed]

5. Lehtonen, H.; Leskinen, E.; SeléN, R.; Reinikainen, M. Potential reasons for the changes in the abundance of pike, Esox lucius, in the western Gulf of Finland, 1939-2007: Changes in pike abundance in the gulf of finland. Fish. Manag. Ecol. 2009, 16, 484-491. [CrossRef]

6. Balik, Ü.; Cubuk, H.; Özkök, R.; Uysal, R. Reproduction Properties of Pike (Esox lucius L., 1758) Population in Lake KaramÝk (Afyonkarahisar/Turkey). Fish. Res. Inst. 2006, 30, 27-34.

7. Muscalu-Nagy, C.; Muscalu-Nagy, R.; Balázs, K. Attempts to increase the growth rhythm of juvenile Northern pike (Esox lucius, L.) by adding enzyme based ingredients into dry feed. Aquac. Aquar. Conserv. Legis. 2013, 6, 99-104.

8. Suguna, P.; Binuramesh, C.; Abirami, P.; Saranya, V.; Poornima, K.; Rajeswari, V.; Shenbagarathai, R. Immunostimulation by poly- $\beta$ hydroxybutyrate-hydroxyvalerate (PHB-HV) from Bacillus thuringiensis in Oreochromis mossambicus. Fish Shellfish Immunol. 2014, 36, 90-97. [CrossRef]

9. Magondu, E.W.; Rasowo, J.; Oyoo-Okoth, E.; Charo-Karisa, H. Evaluation of sodium chloride (NaCl) for potential prophylactic treatment and its short-term toxicity to African catfish Clarias gariepinus (Burchell 1822) yolk-sac and swim-up fry. Aquaculture 2011, 319, 307-310. [CrossRef]

10. Noga, E.J. Fish Disease: Diagnosis and Treatment, 2nd ed.; Iowa State University Press: Ames, IA, USA, 2000.

11. Schnick, R.A. The Impetus to Register New Therapeutants for Aquaculture. Progress. Fish Cult. 1988, 50, 190-196. [CrossRef]

12. Selosse, P.M.; Rowland, S.J. Use of Common Salt to Treat Ichthyophthiriasis in Australian Warmwater Fishes. Progress. Fish Cult. 1990, 52, 124-127. [CrossRef]

13. Garcia Magana, L.; Jimenez Vasconcelos, L.; Rodriguez Santiago, A.; Grano Maldonado, M.; Laffon Leal, S. The effectiveness of sodium chloride and formalin in trichodiniasis of farmed freshwater tilapia Oreochromis niloticus (Linnaeus, 1758) in southeastern Mexico. Lat. Am. J. Aquat. Res. 2019, 47, 164-174. [CrossRef]

14. Lisboa, V.; Barcarolli, I.F.; Sampaio, L.A.; Bianchini, A. Effect of salinity on survival, growth and biochemical parameters in juvenile Lebranch mullet Mugil liza (Perciformes: Mugilidae). Neotrop. Ichthyol. 2015, 13, 447-452. [CrossRef]

15. Zhang, M.; Sun, Y.; Liu, Y.; Qiao, F.; Chen, L.; Liu, W.-T.; Du, Z.; Li, E. Response of gut microbiota to salinity change in two euryhaline aquatic animals with reverse salinity preference. Aquaculture 2016, 454, 72-80. [CrossRef]

16. Edwards, S.L.; Marshall, W.S. Principles and patterns of osmoregulation and euryhalinity in fishes. In Euryhaline Fishes, 1st ed.; McCormick, S.D., Farrell, A.P., Brauner, C.J., Eds.; Academic: Oxford, UK, 2013; Volume 32, pp. 1-44.

17. Engström-Öst, J.; Lehtiniemi, M.; Jónasdóttir, S.H.; Viitasalo, M. Growth of pike larvae (Esox lucius) under different conditions of food quality and salinity. Ecol. Freshw. Fish 2005, 14, 385-393. [CrossRef]

18. Jacobsen, L.; Skov, C.; Koed, A.; Berg, S. Short-term salinity tolerance of northern pike, Esox lucius, fry, related to temperature and size. Fish. Manag. Ecol. 2007, 14, 303-308. [CrossRef]

19. Sunde, J.; Tamario, C.; Tibblin, P.; Larsson, P.; Forsman, A. Variation in salinity tolerance between and within anadromous subpopulations of pike (Esox lucius). Sci. Rep. 2018, 8, 1-11. [CrossRef]

20. Crossman, E.J. Taxonomy and distribution of North American esocids. Am. Fish. Soc. 1978, 11, 13-26.

21. Mohrholz, V.; Naumann, M.; Nausch, G.; Krüger, S.; Gräwe, U. Fresh oxygen for the Baltic Sea-An exceptional saline inflow after adecade of stagnation. J. Mar. Syst. 2015, 148, 152-166. [CrossRef] 
22. Abou Anni, I.S.; Bianchini, A.; Barcarolli, I.F.; Varela, A.S.; Robaldo, R.B.; Tesser, M.B.; Sampaio, L.A. Salinity influence on growth, osmoregulation and energy turnover in juvenile pompano Trachinotus marginatus Cuvier 1832. Aquaculture 2016, 455, 63-72. [CrossRef]

23. Árnason, T.; Magnadóttir, B.; Björnsson, B.; Steinarsson, A.; Björnsson, B.T. Effects of salinity and temperature on growth, plasma ions, cortisol and immune parameters of juvenile Atlantic cod (Gadus morhua). Aquaculture 2013, 380, 70-79. [CrossRef]

24. Urbina, M.A.; Glover, C.N. Effect of salinity on osmoregulation, metabolism and nitrogen excretion in the amphidromous fish, inanga (Galaxias maculatus). J. Exp. Mar. Biol. Ecol. 2015, 473, 7-15. [CrossRef]

25. Brugman, S.; Nieuwenhuis, E.E.S. Mucosal control of the intestinal microbial community. J. Mol. Med. 2010, 88, 881-888. [CrossRef] [PubMed]

26. Viney, M.E.; Riley, E.M. From immunology to eco-immunology: More than a new name. In Eco-Immunology, 1st ed.; Mala-goli, D., Ottaviani, E., Eds.; Springer: Dordrecht, Holland, 2014; pp. 1-19.

27. Wang, A.R.; Ran, C.; Ringø, E.; Zhou, Z.G. Progress in fish gastrointestinal microbiota research. Rev. Aquac. 2018, 10, 626-640. [CrossRef]

28. Ghanbari, M.; Kneifel, W.; Domig, K.J. A new view of the fish gut microbiome: Advances from next-generation sequencing. Aquaculture 2015, 448, 464-475. [CrossRef]

29. Eichmiller, J.J.; Hamilton, M.J.; Staley, C.; Sadowsky, M.J.; Sorensen, P.W. Environment shapes the fecal microbiome of invasive carp species. Microbiome 2016, 4, 44. [CrossRef] [PubMed]

30. Hennersdorf, P.; Kleinertz, S.; Theisen, S.; Abdul-Aziz, M.A.; Mrotzek, G.; Palm, H.W.; Saluz, H.P. Microbial Diversity and Parasitic Load in Tropical Fish of Different Environmental Conditions. PLoS ONE 2016, 11, e0151594. [CrossRef]

31. Kashinskaya, E.N.; Simonov, E.P.; Kabilov, M.R.; Izvekova, G.I.; Andree, K.B.; Solovyev, M.M. Diet and other environmental factors shape the bacterial communities of fish gut in an eutrophic lake. J. Appl. Microbiol. 2018, 125, 1626-1641. [CrossRef]

32. Schmidt, V.T.; Smith, K.F.; Melvin, D.W.; Amaral-Zettler, L.A. Community assembly of a euryhaline fish microbiome during salinity acclimation. Mol. Ecol. 2015, 24, 2537-2550. [CrossRef]

33. Sullam, K.E.; Essinger, S.D.; Lozupone, C.A.; O'Connor, M.P.; Rosen, G.L.; Knight, R.; Kilham, S.S.; Russell, J.A. Environmental and ecological factors that shape the gut bacterial communities of fish: A meta-analysis. Mol. Ecol. 2012, 21, 3363-3378. [CrossRef]

34. Roeselers, G.; Mittge, E.K.; Stephens, W.Z.; Parichy, D.M.; Cavanaugh, C.M.; Guillemin, K.; Rawls, J.F. Evidence for a core gut microbiota in the zebrafish. ISME J. 2011, 5, 1595-1608. [CrossRef]

35. Dulski, T.; Zakęś, Z.; Ciesielski, S. Characterization of the gut microbiota in early life stages of pikeperch Sander lucioperca: Gut microbiota of S. lucioperca. J. Fish Biol. 2018, 92, 94-104. [CrossRef] [PubMed]

36. Komoroske, L.M.; Jeffries, K.M.; Connon, R.E.; Dexter, J.; Hasenbein, M.; Verhille, C.; Fangue, N.A. Sublethal salinity stress contributes to habitat limitation in an endangered estuarine fish. Evol. Appl. 2016, 9, 963-981. [CrossRef] [PubMed]

37. Nossa, C.W. Design of $16 \mathrm{~S}$ rRNA gene primers for 454 pyrosequencing of the human foregut microbiome. World J. Gastroenterol. 2010, 16, 4135. [CrossRef] [PubMed]

38. Klindworth, A.; Pruesse, E.; Schweer, T.; Peplies, J.; Quast, C.; Horn, M.; Glöckner, F.O. Evaluation of general $16 \mathrm{~S}$ ribosomal RNA gene PCR primers for classical and next-generation sequencing-based diversity studies. Nucleic Acids Res. 2013, 41, e1. [CrossRef] [PubMed]

39. Caporaso, J.G.; Kuczynski, J.; Stombaugh, J.; Bittinger, K.; Bushman, F.D.; Costello, E.K.; Fierer, N.; Peña, A.G.; Goodrich, J.K.; Gordon, J.I.; et al. QIIME allows analysis of high-throughput community sequencing data. Nat. Methods 2010, 7, 335-336. [CrossRef] [PubMed]

40. Amir, A.; McDonald, D.; Navas-Molina, J.A.; Kopylova, E.; Morton, J.T.; Zech Xu, Z.; Kightley, E.P.; Thompson, L.R.; Hyde, E.R.; Gonzalez, A.; et al. Deblur Rapidly Resolves Single-Nucleotide Community Sequence Patterns. MSystems 2017, 2. [CrossRef] [PubMed]

41. Parks, D.H.; Beiko, R.G. Identifying biologically relevant differences between metagenomic communities. Bioinformatics 2010, 26, 715-721. [CrossRef]

42. Benjamini, Y.; Hochberg, Y. Controlling the false discovery rate: A practical and powerful approach to multiple testing. J. R. Stat. Soc. 1995, 57, 289-300. [CrossRef]

43. Lozupone, C.; Knight, R. UniFrac: A New Phylogenetic Method for Comparing Microbial Communities. Appl. Environ. Microbiol. 2005, 71, 8228-8235. [CrossRef] 
44. Lozupone, C.A.; Hamady, M.; Kelley, S.T.; Knight, R. Quantitative and Qualitative Diversity Measures Lead to Different Insights into Factors That Structure Microbial Communities. Appl. Environ. Microbiol. 2007, 73, 1576-1585. [CrossRef]

45. Kang'ombe, J.; Brown, J.A. Effect of Salinity on Growth, Feed Utilization, and Survival of Tilapia rendalli Under Laboratory Conditions. J. Appl. Aquac. 2008, 20, 256-271. [CrossRef]

46. Dokuboba, A.; Akinrotimi, O.A.; Dabor, P.O. Effects of Different Physiological Saline Concentrations on the Reproductive Performance of Clarias gariepinus (Burchell, 1822). J. Fish. Sci. 2018, 12, 004-008.

47. Su, B.; Perera, D.A.; Mu, X.; Dunham, R.A. Effect of Sodium Chloride on Hatching Rate on Channel Catfish, Ictalurus punctatus, Embryos. J. Appl. Aquac. 2013, 25, 283-292. [CrossRef]

48. Dehler, C.E.; Secombes, C.J.; Martin, S.A.M. Seawater transfer alters the intestinal microbiota profiles of Atlantic salmon (Salmo salar L.). Sci. Rep. 2017, 7, 1-11. [CrossRef]

49. Dewi, R.R. The Efficacy of Sodium Chloride Application in the Control of Fish Lice (Argulus sp.) infection on Tilapia (Oreochromis niloticus). Acta Aquat. Aquat. Sci. J. 2018, 5, 4-7. [CrossRef]

50. Tacchi, L.; Lowrey, L.; Musharrafieh, R.; Crossey, K.; Larragoite, E.T.; Salinas, I. Effects of transportation stress and addition of salt to transport water on the skin mucosal homeostasis of rainbow trout (Oncorhynchus mykiss). Aquaculture 2015, 435, 120-127. [CrossRef]

51. Romero, J.; Ringø, E.; Merrifield, D.L. The Gut Microbiota of Fish in Aquaculture Nutrition. In Aquaculture Nutrition: Gut Health, Probiotics and Prebiotics, 2nd ed.; Merrifield, D., Ringø, E., Eds.; Wiley-Blackwell Publishing: Oxford, UK, 2014; pp. 75-100.

52. Navarrete, P.; Magne, F.; Araneda, C.; Fuentes, P.; Barros, L.; Opazo, R.; Espejo, R.; Romero, J. PCR-TTGE Analysis of 16S rRNA from Rainbow Trout (Oncorhynchus mykiss) Gut Microbiota Reveals Host-Specific Communities of Active Bacteria. PLoS ONE 2012, 7, e31335. [CrossRef]

53. Li, J.; Ni, J.; Li, J.; Wang, C.; Li, X.; Wu, S.; Zhang, T.; Yu, Y.; Yan, Q. Comparative study on gastrointestinal microbiota of eight fish species with different feeding habits. J. Appl. Microbiol. 2014, 117, 1750-1760. [CrossRef]

54. Liu, H.; Guo, X.; Gooneratne, R.; Lai, R.; Zeng, C.; Zhan, F.; Wang, W. The gut microbiome and degradation enzyme activity of wild freshwater fishes influenced by their trophic levels. Sci. Rep. 2016, 6, 24340. [CrossRef]

55. Givens, C.; Ransom, B.; Bano, N.; Hollibaugh, J. Comparison of the gut microbiomes of 12 bony fish and 3 shark species. Mar. Ecol. Prog. Ser. 2015, 518, 209-223. [CrossRef]

56. Llewellyn, M.S.; Boutin, S.; Hoseinifar, S.H.; Derome, N. Teleost microbiomes: The state of the art in their characterization, manipulation and importance in aquaculture and fisheries. Front. Microbiol. 2014, 5, 207. [CrossRef] [PubMed]

57. Xia, J.H.; Lin, G.; Fu, G.H.; Wan, Z.Y.; Lee, M.; Wang, L.; Liu, X.J.; Yue, G.H. The intestinal microbiome of fish under starvation. BMC Genom. 2014, 15, 266. [CrossRef] [PubMed]

58. Sevellec, M.; Pavey, S.A.; Boutin, S.; Filteau, M.; Derome, N.; Bernatchez, L. Microbiome investigation in the ecological speciation context of lake whitefish (Coregonus clupeaformis) using next-generation sequencing. J. Evol. Biol. 2014, 27, 1029-1046. [CrossRef] [PubMed]

59. Star, B.; Haverkamp, T.H.A.; Jentoft, S.; Jakobsen, K.S. Next generation sequencing shows high variation of the intestinal microbial species composition in Atlantic cod caught at a single location. BMC Microbiol. 2013, 13, 248. [CrossRef]

60. Ramírez, C.; Romero, J. Fine Flounder (Paralichthys adspersus) Microbiome Showed Important Differences between Wild and Reared Specimens. Front. Microbiol. 2017, 8, 271. [CrossRef]

61. Geraylou, Z.; Souffreau, C.; Rurangwa, E.; Maes, G.E.; Spanier, K.I.; Courtin, C.M.; Delcour, J.A.; Buyse, J.; Ollevier, F. Prebiotic effects of arabinoxylan oligosaccharides on juvenile Siberian sturgeon (Acipenser baerii) with emphasis on the modulation of the gut microbiota using 454 pyrosequencing. FEMS Microbiol. Ecol. 2013, 86, 357-371. [CrossRef]

62. Wu, S.; Wang, G.; Angert, E.R.; Wang, W.; Li, W.; Zou, H. Composition, Diversity, and Origin of the Bacterial Community in Grass Carp Intestine. PLoS ONE 2012, 7, e30440. [CrossRef]

63. Schmidt, V.; Amaral-Zettler, L.; Davidson, J.; Summerfelt, S.; Good, C. Influence of Fishmeal-Free Diets on Microbial Communities in Atlantic Salmon (Salmo salar) Recirculation Aquaculture Systems. Appl. Environ. Microbiol. 2016, 82, 4470-4481. [CrossRef] 
64. Egerton, S.; Culloty, S.; Whooley, J.; Stanton, C.; Ross, R.P. The Gut Microbiota of Marine Fish. Front. Microbiol. 2018, 9, 873. [CrossRef]

65. Ringø, E.; Birkbeck, T.H. Intestinal microflora of fish larvae and fry. Aquac. Res. 1999, 30, 73-93. [CrossRef]

66. McIntosh, D.; Ji, B.; Forward, B.S.; Puvanendran, V.; Boyce, D.; Ritchie, R. Culture-independent characterization of the bacterial populations associated with cod (Gadus morhua L.) and live feed at an experimental hatchery facility using denaturing gradient gel electrophoresis. Aquaculture 2008, 275, 42-50. [CrossRef]

67. Zhou, Z.; Yao, B.; Romero, J.; Waines, P.; Ringø, E.; Emery, M.; Liles, M.; Merrifield, D.L. Methodological approaches used to assess fishgastrointestinal communities. In Aquaculture Nutrition: Gut Health, Probiotics and Prebiotics, 2nd ed.; Merrifield, D., Ringø, E., Eds.; Wiley-Blackwell Publishing: Oxford, UK, 2014; pp. 101-127.

68. Lage, O.M.; Bondoso, J. Planctomycetes and macroalgae, a striking association. Front. Microbiol. 2014, 5, 267. [CrossRef] [PubMed]

(C) 2020 by the authors. Licensee MDPI, Basel, Switzerland. This article is an open access article distributed under the terms and conditions of the Creative Commons Attribution (CC BY) license (http://creativecommons.org/licenses/by/4.0/). 